\title{
REVISITANDO OS EFEITOS DA ASSINATURA DE UM TRATADO INTERNACIONAL: DA OBRIGAÇÃO DE BOA-FÉ À SUJEIÇÃO INTERNACIONAL DO ESTADO
}

\author{
Paula Wojcikiewicz Almeida e Maíra Fajardo Linhares Pereira
}

THE OBLIGATIONS OF SIGNATORY STATES OF AN INTERNATIONAL

TREATY: FROM GOOD FAITH TO INTERNATIONAL OBLIGATION

\section{RESUMO}

A NATUREZA DAS OBRIGAC̣̃̃ES IMPOSTAS AO ESTADO QUE ASSINA UM TRATADO INTERNACIONAL FIGURA NA ORDEM DO DIA DOS DEBATES INTERNACIONAIS. ISSO PORQUE MUITOS ESTADOS TÊM ADOTADO A PRÁTICA DE ASSINAR TRATADOS INTERNACIONAIS EM FUNÇÃO DE COMPROMISSOS POLÍTICOS SEM, ENTRETANTO, PRETENDER RATIFICÁ-LOS, CASO QUE ASSUMIRIAM A OBRIGAÇÃO DE RESPEITAR SEU CONTEÚDO. O OBJETIVO DESTE ARTIGO É ANALISAR A GRADAÇÃO E A IMPORTÂNCIA DE TAIS OBRIGAÇÕES NO QUE TANGE AOS TRATADOS EM FORMA SOLENE E AOS TRATADOS EM Forma SIMPLIFICADA. PARA ISSO, RECORREU-SE À ANÁlise DE CONTEÚDO CUJO PONTO DE PARTIDA FOI O TEXTO DA CONVENCÇÃO DE Viena sobre o Direito dos Tratados de INTERPRETAÇÃo E A ANÁLISE DO TEXTO DA CONVENÇÃO FORAM REALIZADAS SEGUNDO OS CRITÉRIOS GRAMATICAL, HISTÓRICO, TELEOLÓGICO E PRÁTICO E FORAM BASEADAS PRINCIPALMENTE NOS DEBATES PRÉVIOS À SUA ADOÇÃo REALIZAdos PELA COMISSÃo dE DIREITO INTERNACIONAL DA ONU E EM TEXTOS DOUTRINÁRIOS. AO FINAL, CONCLUIU-SE QUE, COMO PRETENDERAM OS REDATORES DA REFERIDA CONVENÇ̃̃o, A ASSINATURA TEM TIDO CRESCENTE IMPORTÂNCIA NO QUE TANGE ÀS OBRIGAÇÕES DE UM ESTADO NA ESFERA INTERNACIONAL, PODENDO GERAR, NO CASO DOS ACORDOS EM FORMA SOLENE, UMA OBRIGAÇĀO DE BOA-FÉ QUE NÃO PODERÁ SER NEGLIGENCIADA, E ATÉ MESMO A EFETIVA RESPONSABILIZAC̣ĀO DO ESTADO NO CASO DOS ACORDOS EM FORMA SIMPLIFICADA, QUE ATUALMENTE DOMINAM O CENÁRIO INTERNACIONAL E BRASILEIRO.

\section{PALAVRAS-CHAVE}

Tratados; ACORDOS EM FORMA SIMPLIFICAda; OBRIGAÇÕES; Assinatura; Convenção de Viena sobre o Direito dos TRATADOS; DIREITO INTERNACIONAL.

\begin{abstract}
THE NATURE OF THE OBLIGATIONS IMPOSED ON A STATE WHICH SIGNS AN INTERNATIONAL TREATY IS ONE OF THE MOST DISCUSSED TOPICS IN INTERNATIONAL DEBATES. THIS IS DUE TO THE FACT THAT MANY STATES HAVE ADOPTED THE PRACTICE OF SIGNING INTERNATIONAL AGREEMENTS IN ORDER TO SATISFY POLITICAL DEMANDS, BUT WITHOUT THE INTENTION OF RATIFYING THEM, WHEN THEY WOULD ASSUME RESPONSIBILITY FOR COMPLYING WITH TREATY CONTENT. THE AIM OF THIS ARTICLE IS TO ANALYSE THE DEGREE AND IMPORTANCE OF SUCH OBLIGATIONS CONCERNING BOTH TREATIES AND EXECUTIVE AGREEMENTS. TO THIS END, AN CONTENT ANALYSIS, WHOSE POINT OF DEPARTURE WAS THE TEXT OF THE VIENNA CONVENTION ON THE LAW OF TREATIES WAS UTILIZED. THE INTERPRETATION AND ANALYSIS OF THE TEXT WERE CARRIED OUT FOLLOWING GRAMMATICAL, HISTORICAL, TELEOLOGICAL AND PRACTICAL CRITERIA AND WERE BASED PRINCIPALLY ON DEBATES ORGANISED BY THE INTERNATIONAL LAW COMMISSION PRIOR TO THE ADOPTION of the VienNa CONVENTION, aS WELL AS the ACADEMIC Literature. Finally, it IS CONCLUded that the Signing OF A TREATY HAS BEEN OF GROWING IMPORTANCE REGARDING THE INTERNATIONAL OBLIGATIONS OF A STATE, RANGING FROM AN OBLIGATION OF GOOD FAITH IN THE CASE OF TREATIES TO FULL RESPONSIBILITY FOR COMPLYING WITH THE CONTENT OF AN EXECUTIVE AGREEMENT, WHICH DOMINATES THE INTERNATIONAL AND BRAZILIAN ARENA.
\end{abstract}

\section{KEYWORDS}

TREATIES; EXECUTIVE AGREEMENTS; OBLIGATIONS; SIGNING; Vienna Convention on the LaW of Treaties; INTERNATIONAL LAW. 


\section{INTRODUÇÃO}

A latitude deixada aos Estados acerca do momento da ratificação ${ }^{1}$ de um tratado internacional ${ }^{2}$ produz insegurança jurídica tanto para os demais Estados participantes, que podem ver suas expectativas legítimas frustradas (SCELLE, 1948, p. 618), quanto para os indivíduos, considerados sujeitos de direito internacional (CANÇADO TRINDADE, 2006B). Além disso, a reputação do Estado em espécie poderia ser abalada, assim como a autoridade do próprio direito internacional (ZOLLER, 1977, p. 71). Por um lado, o lapso temporal entre a assinatura e a ratificação pode se estender por quarenta anos, como testemunha a Convenção de Viena sobre o Direito dos Tratados de 1969 (“Convenção de Viena”) que, embora dotada de normas que constituem costume internacional, foi apenas ratificada pelo Brasil em 2009. Por outro lado, a assinatura poderá intervir em momento no qual o Estado não pretendia sujeitar-se internacionalmente, não dando seguimento aos trâmites internos para a devida ratificação do tratado. Tal questionamento veio à tona novamente em 2002, quando a sociedade internacional surpreendeu-se com a decisão do governo Bush de retirar a assinatura aposta no Estatuto de Roma que instituiu o Tribunal Penal Internacional, com vistas a concluir acordos bilaterais com Estados partes do Estatuto, capazes de frustrar o objeto e a finalidade do referido tratado.

Ambas as situações descritas conduzem ao questionamento acerca do efeito das obrigações decorrentes da assinatura para o Estado que demonstrou intenção de tornar-se parte de um tratado internacional. Questionam-se, sobretudo, quais seriam as consequências da assinatura para o direito internacional. Um Estado que assina um tratado para a proibição do uso de determinada arma pode, antes da ratificação, (i) continuar a fazer uso dela; (ii) continuar a adquiri-la; ou mesmo (iii) iniciar sua fabricação até então não realizada? Um Estado que participa das negociações de um tratado de livre comércio pode criar novos impostos ou mesmo aumentar o valor das alíquotas existentes? Aqueles afetados pela criação do novo imposto podem exigir o fim da cobrança alegando descumprimento das obrigações decorrentes da assinatura de um tratado internacional? Tais questionamentos levam a crer que a assinatura não é apenas uma simples formalidade acessória no processo de conclusão de um tratado internacional (ZOLLER, 1977, p. 69), pois favorece o nascimento de obrigações para os Estados signatários, principalmente a indiscutível obrigação de boa-fé prevista no artigo 18 da Convenção de Viena.

Cabe destacar que a obrigação de boa-fé somente é aplicável aos Estados signatários contratantes de um tratado propriamente dito ou acordo em forma solene (DINH; DAILLIER; PELLET, 2003, p. 139-140), o qual determina que o consentimento em obrigar-se é configurado com a ratificação. Neste caso, a assinatura estará sujeita à ratificação, devendo o Estado realizar dois atos sucessivos - assinatura e ratificação - para submeter-se ao tratado. Com efeito, as mesmas regras não se aplicam quando a assinatura é suficiente para exprimir o consentimento definitivo de um Estado em obrigar-se 
por um tratado, coincidindo com sua entrada realização de um único ato para a submissão do Estado ao tratado, considerado Estado signatário parte, confere brevidade ao processo de conclusão, motivo pelo qual a prática dos acordos em forma simplificada ou executive agreements têm se desenvolvido como uma resposta às necessidades da sociedade internacional contemporânea (VISSCHER, 1952, p. 536). ${ }^{3}$ Assim sendo, de acordo com as fases necessárias a fim de que um Estado possa sujeitar-se a um tratado internacional, ${ }^{4}$ o processo de celebração será considerado breve, típico dos acordos em forma simplificada, ou mesmo longo, como ocorre no caso dos acordos em forma solene.

Tendo em vista o exposto, não restam dúvidas de que as obrigações impostas às partes no caso de acordos em forma simplificada são distintas daquelas oponíveis às partes de um acordo em forma solene. O objetivo deste artigo é, portanto, analisar os efeitos da assinatura em ambos os casos, que podem evoluir desde a obrigação de boa-fé (parte 1 deste artigo) até a efetiva sujeição do Estado, que repercute na possibilidade de engajar sua responsabilidade internacional em caso de descumprimento do tratado. Esta última hipótese somente poderia restar configurada após a admissão da prática dos acordos em forma simplificada, objeto de grandes debates tanto no âmbito nacional quanto internacional (parte 2 deste artigo).

\section{EFEITOS DA ASSINATURA DE UM TRATADO EM FORMA SOLENE:}

UMA OBRIGAÇÃO DE BOA-FÉ

O que caracteriza os tratados em forma solene é a sujeição do Estado por meio de dois atos sucessivos, a assinatura e a ratificação. Somente com a realização do segundo é que o Estado torna-se obrigado pelas cláusulas do tratado. Desta forma, a conclusão do tratado, identificada pela assinatura do Estado, engendra uma situação jurídica intermediária entre a adoção do texto e a sujeição ao tratado pelo Estado. A assinatura não pode ser identificada como um mero ato de autenticação, mas também não é suficiente para sujeitar o Estado a todas as obrigações impostas pelo tratado. Caso contrário, a separação entre as fases de conclusão e sujeição seria desnecessária, assim como a própria ratificação. Com vistas a identificar os direitos e deveres de um Estado contratante resultantes da assinatura de um tratado em forma solene, será preciso analisar a alínea “a” do artigo 18 da Convenção de Viena sobre o Direito dos Tratados. ${ }^{5}$ A interpretação realizada neste trabalho observará os critérios clássicos da hermenêutica jurídica: gramatical, sistemático, teleológico, histórico e prático (LARENZ, 1997). A Convenção de Viena preconiza a utilização destes mesmos critérios para a interpretação dos tratados (artigos 31 e 32), não tendo fixado nem uma hierarquia nem uma obrigação da utilização destes, que são apenas apresentados em uma ordem lógica de sucessão. A escolha dos critérios a serem utilizados e a relevância atribuída a cada um deles cabe ao intérprete, que deve fazê-lo de boa-fé (ONU, 
1971, p. 37-43). Esta interpretação conduzirá à dupla distinção entre as obrigações que incumbem ao Estado perante o direito internacional previstas no artigo 18 supracitado. Tal artigo, apesar de não mencionar expressamente o direito do Estado contratante de não adotar atos posteriores tendentes a confirmar sua assinatura, poderá ser interpretado no sentido de conferir ao referido Estado a possibilidade de recusar a ratificação, o que não será feito sem o respeito de certas condições (item 1.1, a seguir). Com efeito, a parte final do artigo 18 não deixa dúvidas sobre esta opção. Paralelamente, há uma limitação na atuação estatal ao estabelecer expressamente o dever de "abster-se da prática de atos que frustrariam o objeto e a finalidade de um tratado" (item 1.2, a seguir).

\section{I OS LIMITES DA LIBERDADE DE RECUSAR A RATIFICAÇÃO}

A assinatura constitui um ato voluntário do Estado que deve ser considerado uma expressão geral, ainda que provisória, de apoio ao texto (ONU, 1965, p. 51). O texto apresentado para assinatura será a base do futuro acordo, que somente passará a existir com a ratificação (ONU, 1956, p. 112 e 121). Com base nestas observações, pode-se concluir que a redação do artigo 18 poderia ser compreendida como a manifestação estatal de não mais se tornar parte do tratado, já que o Estado havia manifestado sua vontade no momento da assinatura, independentemente de seu direito de confirmá-la ou não posteriormente.

O argumento é reforçado pelo fato de que uma das propostas de redação do atual artigo 18 incluía a obrigação de submeter o texto ao exame das autoridades constitucionais competentes do Estado contratante para sua aprovação ou rejeição. Lauterpacht, relator especial da Comissão de Direito Internacional das Nações Unidas durante os anos de 1953 e 1954, ponderou que se a norma fosse redigida de tal forma expressaria uma obrigação de ratificação pelo Estado em caso de aprovação pelo órgão competente (ONU, 1953, p. 108). Foi debatida também a obrigatoriedade de ratificação caso a assinatura fosse dada por plenipotenciário cujos poderes incluíssem, além da autorização para negociar, a possibilidade de concluir tratados internacionais. Contudo, nenhuma dessas opiniões baseava-se em práticas existentes e, portanto, não poderia constituir costume internacional. Apesar disso, para Lauterpacht, a obrigação de submeter o tratado, logo após a devida assinatura, às autoridades competentes do Estado para sua aprovação ou rejeição deveria ser vista como uma exigência decorrente da boa-fé. Ora, a proposta de Lauterpacht reflete uma expectativa legítima e coerente, extraída da manifestação do Estado no momento da assinatura.

Com efeito, embora um direito, a recusa em ratificar não poderia ser exercida de forma caprichosa ou arbitrária (ONU, 1953, p. 109). A assinatura constitui um ato de boa-fé, ao qual os Estados devem respeito não somente por uma questão de prudência política, como manter-se confiável perante outros Estados, mas também 
por uma questão de direito. Um Estado contratante deve agir de forma coerente com as responsabilidades resultantes de seu ato, exercendo importante influência sobre algumas cláusulas, tais como direito de adesão, possibilidades de $\operatorname{reservas}^{6} \mathrm{e}$ condições para a entrada a negociação, as normas serão construídas com base em concessões mútuas de um Estado em função do comprometimento de outro e/ou para garantir sua participação.

Não restam dúvidas de que "a ratificação é o resultado natural e o propósito da assinatura”, razão pela qual todo Estado que pretenda recusar a ratificação de um tratado regularmente assinado deverá indicar as razões para tanto (ONU, 1953, p. 110). Nessa linha, os motivos pelos quais um Estado justificará sua decisão de recusa em ratificar um tratado são semelhantes àqueles que justificam a retirada unilateral do tratado ou o seu descumprimento e, assim como nestes casos, devem ser empregados excepcionalmente (ONU, 1953, p. 112). Dessa forma, algumas dessas razões podem ser extraídas da própria Convenção por meio da extensão dos artigos que tratam da retirada unilateral e do descumprimento ao momento da ratificação. As razões para a recusa da ratificação podem ser classificadas, para fins didáticos, em independentes (item 1.1.1, a seguir) ou dependentes (item 1.1.2, a seguir) da vontade estatal.

\section{I. I As RAZÕes INDEPENDENTES DA VONTADE Do Estado}

A Convenção de Viena prevê em seu artigo 61, relativo à "impossibilidade superveniente de cumprimento", uma das razões para o descumprimento de um tratado. Trata-se da impossibilidade de cumprimento resultante da destruição ou desaparecimento de um objeto indispensável ao cumprimento do tratado, desde que a responsabilidade não possa ser atribuída a nenhuma das Partes. Logo, um Estado também poderá recusar a ratificação de um tratado caso haja perda de um objeto indispensável no período entre a assinatura e a ratificação. Ademais, mudanças fundamentais nas circunstâncias existentes no momento da conclusão, não previstas pelas partes, representadas pelo princípio rebus sic stantibus, são aceitas excepcionalmente para o descumprimento de tratados. As condições para que uma mudança circunstancial possa ser aceita estão previstas no artigo 62 da Convenção de Viena. Estas mesmas condições deverão ser observadas quando o princípio rebus sic stantibus for usado para justificar a recusa em ratificar.

O artigo 62 foi aprovado pelos negociadores e contratantes por constituir costume internacional e ser amplamente aceito pela doutrina jus-internacionalista, mas com a ressalva de que deveria ser cuidadosamente delimitado e regulado, uma vez que as circunstâncias na vida internacional estão sempre em transformação (ONU, 1971, p. 76-79). Dessa forma, justificativas com base em mudanças fundamentais só serão válidas quando afetarem situações tacitamente consideradas condição para a aceitação do acordo, desde que o Estado alegue sua existência de boa-fé e em período razoável de tempo após terem sido notadas. 
Se as razões independentes da vontade do Estado para a recusa da ratificação podem ser facilmente delimitadas e identificadas nos textos internacionais, esse não é o caso daquelas que dependem da vontade estatal, submetidas seja às normas internacionais seja às normas constitucionais vigentes.

\section{I . I. 2 AS RAZÕES DEPENDENTES DA VONTADE DO ESTADO}

Algumas vezes o próprio tratado prevê a possibilidade de um Estado contratante retirar-se do tratado sem a necessidade de apresentar qualquer justificativa, bastando a simples manifestação de sua vontade e o respeito a prazos preestabelecido e outras possíveis formalidades. Se o tratado assinado contiver este tipo de previsão, o Estado signatário contratante que não quiser ratificá-lo também não será obrigado a apresentar justificativas, bastando a manifestação de sua intenção de não ratificar. Se o tratado não contiver disposições para a retirada unilateral, a regra geral é a de que este tratado não é passível de denúncia ou retirada. As exceções admitidas estão previstas no artigo 56 da Convenção de Viena que trata da denúncia ou retirada de um tratado que não contém disposições sobre extinção, denúncia ou retirada. Desse modo, a recusa em ratificar, quando não há previsão de denúncia ou retirada, também só deveria ser admitida nas circunstâncias previstas pelo artigo 56. Contudo, a recusa em ratificar pode ser justificada por uma razão exclusiva que não consta no rol das justificativas para a denúncia ou retirada - a não aprovação do tratado pelo Poder Legislativo.

Por motivos históricos, a aprovação legislativa tem sido apontada como a razão de ser da ratificação (ONU, 1953, p. 111-112). Logo, a falta desta aprovação, apesar de se tratar de fixação de competências do direito interno, é, sem dúvida, uma das razões pelas quais a ratificação poderá ser negada. No quadro dos regimes representativos e democráticos, a maior parte dos tratados não ratificados permanece sendo motivada pelo desacordo entre Legislativo e Executivo (DINH; DAILLIER; PELLET, 2003, p. 143). ${ }^{7}$ Assim, a recusa em ratificar baseada na não aprovação do Legislativo deve ser vista como exceção à regra de que um Estado não pode invocar normas de direito interno para retirar seu consentimento de um tratado ou recusar a ratificação. Com efeito, a regra cede se a violação for manifesta e disser respeito a uma norma interna de importância fundamental (vide artigo 46 da Convenção de Viena sobre direito dos tratados), como é o caso das normas constitucionais e de determinadas normas infraconstitucionais que tratam especificamente da competência dos poderes do Estado para a celebração de tratados (CACHAPUZ DE MEDEIROS, 1995, p. 263-269). O direito de invocar normas de direito interno está, portanto, limitado aos casos em que a violação for objetivamente evidente para qualquer Estado que proceda em conformidade com prática normal e a boa-fé. Desta forma, estendendo tal interpretação aos casos de recusa em ratificar um tratado, um Estado poderá apresentar outras justificativas baseadas em suas normas internas, desde que 
a exigência interna necessária para a ratificação seja evidente para qualquer Estado que proceda de boa-fé.

A recusa em ratificar também poderá resultar de omissão do Executivo, após a devida aprovação do tratado pelo Legislativo, nos termos das normas constitucionais vigentes. Isso porque o ato de ratificar um tratado, previamente aprovado pelo Legislativo, é discricionário do Executivo. Com efeito, enquanto a necessidade de aprovação é indispensável à ratificação, a aprovação não implica necessariamente a ratificação que, contudo, não poderá ser negada levianamente. Outrossim, a omissão do Executivo poderá decorrer de longo espaço de tempo entre a assinatura pelo Executivo e a entrega do tratado ao Legislativo para devida aprovação. Essa situação contraria a expectativa legítima entre Estados contratantes no sentido de que este seria entregue para o exame do Poder Legislativo. A liberdade de escolha acerca do momento de entrega constitui poder discricionário do Executivo e poderá ser feita, segundo alguns doutrinadores, por razões de pura oportunidade política (DINH; DAILLIER; PELLET, 2003, p. 143). O que não significa que o Legislativo também não possa se utilizar de tal mecanismo, retendo o tratado por longos períodos antes de sua devolução ao Executivo. ${ }^{8}$

Ambas as situações descritas, que decorrem de atos ou omissões seja do Poder Executivo seja do Poder Legislativo, ocorrem em situação intermediária na qual o Estado que assinou um tratado internacional não apresentou recusa em ratificar ou ainda não procedeu à ratificação. ${ }^{9}$ Não restam dúvidas, portanto, de que a recusa em ratificar é permitida, desde que devidamente justificada. Entretanto, é importante frisar que não são consideradas razões para a referida recusa mudanças de governo, administração, dinastia ou regime, pois não afetam o princípio da identidade e da continuidade do Estado, essencial para garantir a independência estatal e a estabilidade das relações internacionais. Se as mudanças citadas justificassem o descumprimento de tratados ou a sua não ratificação, os Estados, por um lado, teriam motivos para intervir na política interna uns dos outros e, por outro, hesitariam em fazer acordos de longa duração, temendo possíveis mudanças futuras (ONU, 1956, p. 43, 54-58). Apesar de submetida a certas limitações, a liberdade estatal exercida no momento prévio à ratificação é apontada como uma fonte de atraso e incerteza (DINH; DAILLIER; PELLET, 2003, p. 143). Ora, tal liberdade não tem o condão de elidir seu dever de não realizar atos capazes de frustrar o objeto e a finalidade do tratado. Com efeito, esta obrigação continua sendo exigível enquanto o Estado não manifestar sua intenção de não ratificá-lo, não importando o lapso temporal transcorrido após a assinatura, como será visto em seguida.

\section{I.2 A Obrigação de não Privar um tratado de SeU objeto E Finalidade}

A Comissão de Direito Internacional havia proposto a instituição do dever estatal de não frustrar o objeto e a finalidade de um tratado desde o início da fase das negociações 
(ONU, 1971, p. 22), o que não prosperou por não constituir fruto da prática internacional. Esta previsão foi, portanto, excluída do texto da Convenção, tendo sido objeto de propostas de emendas de vários Estados (ONU, 1971, p. 130-132) e devidamente aprovada por 50 votos a favor a 33 contra e 11 abstenções. De acordo com os Estados que apresentaram as emendas, a obrigação de boa-fé prevista na alínea "a": (i) deveria ser exigida somente quando o princípio pacta sunt servanda estivesse claramente presente, ou seja, os Estados só poderiam se obrigar quando conhecessem o conteúdo do tratado, o qual ainda não estaria definido no momento das negociações, sem conhecimento do conteúdo também não seria possível afirmar quais os atos capazes de frustrá-lo; (ii) poderia inibir as negociações e dissuadir os Estados de delas participarem; (iii) criaria um novo princípio de direito internacional, o que iria além do escopo da codificação; (iv) não derivava da doutrina, da prática, nem dos julgamentos de casos internacionais; e (v) violaria a soberania dos Estados (ONU, 1971, p. 97-106).

A redação final da alínea "a" do artigo 18 da Convenção de Viena contentou-se em fixar a obrigação do Estado contratante de abster-se de atos que frustrariam o objeto e a finalidade do tratado previamente à ratificação, ou seja, no período entre a assinatura e a ratificação. Esta obrigação somente foi incluída na Convenção porque os Estados negociadores assim votaram (ONU, 1971, p.130-132), reconhecendo a existência de um costume já consolidado. Com efeito, a referida obrigação está contida em diversos tratados internacionais (ONU, 1965, p. 88), tendo sido igualmente reconhecida pela jurisprudência internacional (ONU, 1971, p. 100-101 e ZOLLER, 1977, p. 75) . O caso relativo a certos interesses alemães na Alta Silésia polaca, ${ }^{10}$ que tratava da cessão, por parte da Alemanha, de uma porção de seu território para a Polônia, suscitou discussão referente às obrigações que competem ao Estado no período entre a assinatura e a ratificação de um tratado, já que a Alemanha teria promovido, nesse ínterim, a venda das propriedades públicas localizadas na porção destinada à cessão. A Corte decidiu que a Alemanha não havia ultrapassado, com a alienação, os limites da administração normal da propriedade pública e que não tinha tido a intenção de privar a Polônia do direito previsto pelo tratado.

Se a existência da obrigação de boa-fé do Estado contratante ou obrigação interina é, desta forma, reconhecida e aceita pelos Estados, o que precisa ser definido é que tipo de ato frustraria o objeto e a finalidade de um tratado (item 1.2.1, a seguir), bem como a respectiva duração da obrigação (item 1.2.2, a seguir).

\section{I.2. I OS ATOS CAPAZES DE FRUSTRAR O OBJETO E A FINALIDADE DE UM TRATAdo}

A determinação dos critérios definidores de um ato violador não é uma questão muito clara. Com objetivo de determinar estes critérios, três testes poderão ser realizados: (i) um objetivo que busca saber se o acordo ainda poderá ser executado após a prática do ato em questão; (ii) um subjetivo que avalia a intenção do Estado ofensor, devendo-se avaliar se o ato ocorreu por negligência ou por dolo; e (iii) um subjetivo 
que avalia as expectativas legítimas do Estado agredido (KLABBERS, 2001, p. 4). Questiona-se acerca da adequação de tais métodos para a determinação da violação da obrigação interina.

De todo modo, da interpretação gramatical do artigo 18 extrai-se que não foi feito uso de nenhuma expressão que sugerisse a necessidade de um critério subjetivo, seja da intenção do Estado violador ou das expectativas dos demais Estados contratantes ou de eventuais interessados. Entretanto, uma interpretação histórica, com base nos debates anteriores à conclusão da Convenção, pode auxiliar na identificação dos referidos critérios. Ainda que o tema específico não tenha sido objeto de discussão pelos participantes dos debates, algumas indicações podem ser extraídas, principalmente quando observadas as diferentes propostas de redação que culminaram com a aprovação da versão definitiva do artigo 18, determinando a obrigação interina. As propostas vão desde o reconhecimento da importância do critério subjetivo, que conjuga a intenção do ofensor e as expectativas do ofendido (item "a”, a seguir), até a admissão de um critério objetivo (item "b”, a seguir), que prevaleceu na última versão do referido artigo 18 .

a) A discussão acerca do critério subjetivo

A versão que aparece no relatório de Lauterpacht, na $5^{\mathrm{a}}$ sessão da Comissão de Direito Internacional de 1953, ${ }^{11}$ afirma que a assinatura implica a obrigação, a ser realizada de boa-fé, de o Estado abster-se, antes da ratificação, de qualquer ato planejado substancialmente a afetar o valor do que foi assinado. Em seus comentários, Lauterpacht afirma que o ato condenável é somente aquele planejado e não qualquer ato contrário ao tratado, o propósito da norma seria proibir a ação deliberadamente de má-fé para privar a outra parte dos benefícios que espera legitimamente alcançar por meio do tratado, ao qual deu a devida consideração (ONU, 1953, p. 110). Logo, parece que para Lauterpacht o critério deveria ser subjetivo, considerando tanto a intenção do ofensor quanto as expectativas do ofendido. Versão semelhante é apresentada no relatório de Fitzmaurice, na $8^{a}$ sessão da Comissão de Direito Internacional de 1956, o qual se refere à obrigação de não realizar nenhuma ação calculada para afetar ou prejudicar os objetos do tratado. Fitzmaurice, em seus comentários, limita-se a dizer que as razões para tal obrigação foram tratadas por Lauterpacht no relatório de 1953 e que concorda com elas, mas que seria desejável que a proposição fosse tratada em termos um pouco mais cuidadosos e qualificados (ONU, 1956, p. 8 e 122). Dessa forma, Fitzmaurice parece concordar também com a utilização dos critérios subjetivos.

A versão debatida na $17^{\mathrm{a}}$ sessão da Comissão de Direito Internacional em 1965 não apresentou diferença substancial em relação àquela apresentada em 1956 ao referir-se à obrigação de boa-fé de o Estado abster-se de “atos calculados” para frustrar o objeto do tratado. A intervenção do representante da França, Paul Reuter, merece 
atenção por tratar mais diretamente da questão. Reuter considera que a redação então proposta apresenta um caráter objetivo ao se referir ao objeto do tratado, não analisando o valor da expressão "calculados". Contudo, questiona a possibilidade de definição do objeto sem uma avaliação das expectativas das partes envolvidas. Por isso, sugere a alteração do texto para a obrigação de o Estado abster-se de atos calculados para desapontar as expectativas legítimas de seus parceiros. Sugere também a retirada da expressão boa-fé por considerá-la juridicamente imprecisa (ONU, 1965, p. 88-91). Na mesma sessão, o representante da Itália, Roberto Ago, questionou a diferença existente entre um tratado multilateral, no qual dificilmente o ato isolado de uma das partes seria capaz de frustrar seu objeto, e um tratado bilateral, no qual o ato de uma das partes seria suficiente para tanto. Possivelmente Ago estava se referindo à diferença entre tratado normativo e tratado contratual (ONU, 1965, p. 92).

Apesar dos pontos levantados por Roberto Ago, não houve discussão aprofundada sobre as diferenças entre os tratados contratuais e os tratados normativos nos debates que antecederam a conclusão da Convenção de Viena de 1969, o que poderia ter sido útil para a correta interpretação da obrigação prevista no artigo 18 (KLABBERS, 2001, p. 12). Os relatórios da Comissão de Direito Internacional concentram-se, sobretudo, nos tratados contratuais, uma vez que estes constituíam a totalidade dos exemplos fornecidos à época. Entretanto, esta análise não é suficiente para compreender a obrigação no caso dos tratados normativos, já que os testes propostos não seriam adequados a este tipo de tratado. Questiona-se, portanto, como delimitar os efeitos decorrentes da assinatura de tratados normativos, que atualmente constituem grande parte da atividade jurídica da sociedade internacional. ${ }^{12}$

Nos tratados normativos, é preciso ter cuidado para não confundir atos que frustrariam o objeto e a finalidade com os atos que violariam as obrigações assumidas com o tratado. ${ }^{13}$ No entanto, podem existir situações nas quais o ato de um dos Estados contratantes não seja considerado adequado em relação ao objeto e/ou finalidade, mas não cause danos nem viole diretamente as expectativas dos demais sujeitos do tratado. Seria o caso, por exemplo, da aquisição, e não do uso, de determinadas armas que serão proibidas caso o tratado que as condena seja ratificado e entre esse motivo, seria importante avaliar o fator subjetivo relacionado às intenções do responsável pelo ato que violou as expectativas legítimas de um ou mais dos sujeitos do tratado. ${ }^{14}$

\section{b) A prevalência do critério objetivo}

A questão da utilização de critérios subjetivos ou objetivos aparece novamente na $18^{\text {a }}$ sessão em 1966, quando alguns participantes, observando uma diferença de sentido entre as expressões utilizadas na versão inglesa (acts calculated to) e na versão francesa (acts de nature a), sugeriram propostas de emprego de novas expressões. Merecem ser destacadas as propostas que foram aprovadas: (i) a de Ago que sugeriu que a expressão francesa fosse substituída por acts tendant a para acompanhar o elemento de intenção 
da expressão inglesa; e (ii) a proposta do relator Waldock que modificou a expressão inglesa para tending to (ONU, 1966, p. 326).

Apesar de o objetivo da sugestão de Ago ter sido dar à expressão francesa o mesmo caráter intencional da expressão inglesa calculated to, isso não foi o que ocorreu, principalmente porque a expressão inglesa também foi substituída por tending to. A sugestão de Waldock provavelmente foi feita visando uma melhor correspondência entre as versões. Em uma consideração mais atenta, a expressão calculated to apresenta um elemento mais subjetivo do que as expressões tendant a e tending to. Quando se pensa em atos calculados, há uma referência mais latente com o sujeito responsável pelos atos; em outras palavras, o agente precisa ter planejado os atos para que eles provoquem certas consequências. Já quando se pensa em atos tendentes a, o sujeito é deixado de lado, isto é, os atos tendem a provocar determinadas consequências ainda que o sujeito não tenha agido racionalmente no mesmo sentido. Com isso, o caráter subjetivo deixou de estar expresso no artigo que codificou a obrigação interina. A redação do artigo ganhou ainda mais objetividade com a adoção da emenda proposta pela Austrália que sugeriu a substituição da expressão tending to, em razão da dificuldade em interpretá-la, para which would.

É importante ressaltar que o teste objetivo também não está isento de falhas. A grande dificuldade está na determinação do objeto e da finalidade do tratado e na própria definição de quais seriam os atos capazes de frustrar tal objeto e tal finalidade a ponto de invalidar a celebração do tratado, dado os diferentes interesses e interpretações dos Estados contratantes. A dificuldade persiste mesmo quando um terceiro é chamado a fixar tais conceitos, que corre o risco de retomar os testes subjetivos supracitados para a conclusão de sua tarefa. Ora, a vantagem em afastar o critério subjetivo está em se evitar debates sobre as expectativas dos sujeitos e as intenções das partes do tratado, especialmente no caso dos tratados normativos, bem como em abandonar a necessidade de provar a má-fé do agente.

Desta forma, os atos que o artigo 18 da Convenção faz menção seriam aqueles que parecem ser contrários ao tratado, mas que não seriam suficientes para invalidá-lo ainda quando realizados isoladamente ou por somente um dos Estados contratantes. Um ato será contrário a um tratado quando sua interpretação, realizada pela comunidade internacional enquanto ente personificado, assim o considerar com base nos princípios e nos costumes de direito internacional.

\section{I.2.2 A DURAÇÃO DA OBRIGAÇÃO INTERINA}

Tendo em vista o exposto acima, não restam dúvidas de que a obrigação interina inicia-se com a assinatura de um tratado, assim como a ratificação fixa o início da sujeição total do Estado às normas do tratado, tornando obsoleta a obrigação interina. O período entre a assinatura e a ratificação é regulado pelo artigo 18 da Convenção de Viena. Entretanto, resta saber se há limite temporal durante o qual o Estado permanecerá obrigado pelas 
disposições do referido artigo que tratam da exigência de boa-fé, caso não ratifique o tratado.

A interpretação gramatical da parte final da alínea "a" do artigo 18 deixa claro que a obrigação permanecerá enquanto o Estado não tiver manifestado a sua intenção de não se tornar parte no tratado. Assim, o artigo optou por não fixar um prazo determinado, tal como ocorre na fase de ratificação do tratado. A ausência de prazo para a ratificação produz uma obrigação interina quase ilimitada. A versão do relatório de Fitzmaurice, apresentado na $8^{a}$ sessão da Comissão de Direito Internacional de 1956 determinava que a obrigação interina seria exigível enquanto pendente a decisão final sobre a ratificação ou durante um período razoável, mas não foram feitos esclarecimentos sobre o período considerado razoável (ONU, 1956, p. 112 e 121). Durante os debates da $17^{\mathrm{a}}$ sessão da Comissão de Direito Internacional de 1965 , o relator Humphrey Waldock propôs a inclusão do prazo de dez anos após a assinatura para o término da obrigação. Contudo, tal sugestão não foi acatada porque os participantes divergiram com relação à adequação do referido prazo. Argumentou-se que o tempo necessário entre assinatura e ratificação poderia depender do tipo do tratado (ONU, 1965, p. 88-94).

Dessa forma, para se desobrigar dos efeitos decorrentes da assinatura, é necessário que o Estado manifeste sua intenção de não mais fazer parte do tratado. Contudo, a redação do artigo 18 não diz nem como esta manifestação deve ser feita e nem a quem deve ser dirigida. Waldock, também na $17^{\mathrm{a}}$ sessão, sugeriu que o texto do artigo deveria impor ao Estado o dever de notificar os demais Estados contratantes a renúncia do seu direito em ratificar. Essa sugestão foi considerada excessiva pelos participantes da sessão (ONU, 1965, p. 92). O artigo referente à obrigação interina ainda foi debatido em duas reuniões posteriores, sendo que na segunda foi proposta redação no sentido de que a obrigação permaneceria até que o Estado tivesse deixado claro que ele não pretendia se tornar parte do tratado. Tal texto foi criticado por vários participantes que o julgaram vago. Foram feitas sugestões que pediam a inclusão da obrigação de notificar a intenção de não se tornar parte aos outros Estados, bem como o uso de expressões mais significativas como "notificar" ou "declarar"; o uso do verbo "expressar", o que faria com que um discurso público do chefe de Estado fosse suficiente para terminar com a obrigação interina. Houve proposta defendendo que a intenção de um Estado não precisa ser necessariamente notificada ou expressamente manifestada. Diante da dificuldade de um consenso, optou-se pela devolução do artigo ao comitê de elaboração (ONU, 1965, p. 262-263). Na terceira reunião foi apresentado e aprovado o texto que acabou por se tornar a versão definitiva, que determina a duração da obrigação até que o Estado tenha tornado clara sua intenção de não fazer parte do tratado (ONU, 1965, p. 282-283).

A opção por tal redação considerada aberta, após todas as sugestões apresentadas, indica que não há uma única forma para que os Estados possam manifestar a intenção 
de não mais se tornar parte de um tratado, podendo inclusive ocorrer por meio de notificação aos demais Estados contratantes. Contudo, a notificação não deve ser vista como um ato obrigatório. Com efeito, situações nas quais Estados manifestaram expressamente a intenção de não mais se tornar parte de um tratado após a assinatura eram raros, até que em maio de 2002 os EUA enviaram uma carta ${ }^{15}$ ao, então, Secretário Geral da ONU, Kofi Annan. Por meio desta carta, os EUA notificaram os demais Estados contratantes do Tratado de Roma sua intenção de não mais se tornar parte do Estatuto de Roma que institui o Tribunal Penal Internacional, libertando-se da obrigação interina. Mediante este ato, não haveria qualquer obstáculo jurídico para a realização de atos que frustrariam o objeto e a finalidade do tratado. ${ }^{16}$ Se a retirada da assinatura da maneira como realizada pelos EUA poderia ser apontada como a melhor forma de manifestar a intenção de não mais fazer parte de um tratado (SCOTT, 2002, p. 1475), ${ }^{17}$ há quem sustente que a recusa dos EUA, no caso específico do Estatuto de Roma, teria sido abusivamente apresentada como uma retirada de assinatura, quando se tratou simplesmente da recusa em ratificar (DINH; DAILLIER; PELLET, 2003, p. 144). Entretanto, nos termos do artigo 18, o ato dos EUA poderá efetivamente ser considerado uma retirada de assinatura, ato que liberou o Estado da obrigação interina, o que não ocorreria com a simples recusa em ratificar.

De todo modo, é importante frisar que a assinatura não pode ser dada de forma leviana, pois constitui uma primeira manifestação da intenção do Estado de se tornar parte de um tratado. Assim como a recusa em ratificar deve ser justificada, a retirada da assinatura também deve ser. Uma vez analisados os efeitos da assinatura de um acordo em forma solene, que se aperfeiçoa com a ratificação, caberá avaliar os efeitos daqueles acordos nos quais a assinatura marca a sujeição do Estado, coincidindo com sua entrada , os acordos em forma simplificada constituem a maior parte dos compromissos internacionais firmados entre Estados, daí a importância de sua análise.

\section{OS EFEITOS DA ASSINATURA DE UM ACORDO EM FORMA SIMPLIFICADA:}

\section{UMA OBRIGAÇÃO INTERNACIONAL DE CUMPRIMENTO}

A conclusão de um tratado, considerado um "ato convencional por excelência" (CARREAU, 2007, p. 122), está subordinada às exigências constitucionais que determinam as condições nas quais um Estado poderá assumir obrigações na ótica internacional (BASDEVANT, 1926, p. 577). Como o direito internacional não pode determinar os meios técnicos de expressão do consentimento estatal em se obrigar por um tratado internacional, ${ }^{18}$ tais meios decorrem exclusivamente da ordem interna. Entretanto, a prática estatal houve por bem moldar-se às necessidades decorrentes da evolução da sociedade contemporânea, marcadas pelo surgimento dos acordos em forma simplificada (item 2.1, a seguir). Tais acordos tornam-se exigíveis para o Estado a partir do momento da assinatura, não exigindo, portanto, ato posterior de ratificação, 
contrariamente aos acordos em forma solene, como foi visto anteriormente. A assinatura é suficiente para obrigar o Estado na ótica internacional, não se restringindo à obrigação de boa-fé anteriormente anunciada. No Brasil, a conclusão e a recepção dos tratados internacionais seguiram a prática constitucional moderna no sentido de admitir acordos sem intervenção obrigatória do Poder Legislativo, cristalizando, nacionalmente, o uso dos acordos em forma simplificada (item 2.2, a seguir).

\section{I O SURGIMENTO DOS ACORDOS EM FORMA SIMPLIFICADA}

A té o final do século XVIII, a conclusão dos tratados era sempre submetida à vontade absoluta dos monarcas (CACHAPUZ DE MEDEIROS, 1983, p. 24; ARAÚJJ, 1958 , p. 147). A validade interna de um tratado não era questionada porque o príncipe sempre poderia estabelecer sua primazia (MIRKINE-GUETZÉVITCH, 1931, p. 357-358). A política externa era um assunto de competência exclusiva dos príncipes, sendo totalmente excluída da participação dos governados. Estes últimos apenas passaram a participar da política externa após a Revolução Francesa, que produziu uma mudança substancial no direito constitucional da época por meio da introdução da "fórmula moderna do controle parlamentar da política externa" (MIRKINE-GUETZÉVITCH, 1931, p. 360). O Parlamento passou a desempenhar um papel primordial na conclusão de tratados e na condução das relações exteriores, na linha do que dispunha a primeira constituição escrita de previsão de controle do Poder Legislativo, como exigência da sociedade democrática, constituiu regra geral nos textos constitucionais que efetuam a repartição de competências entre o Poder Executivo e o Legislativo em matéria de conclusão de tratados internacionais (item 2.1.1, a seguir). Entretanto, o direito internacional não se encontra apenas nos textos (VISSCHER, 1952, p. 537), sendo resultado eminentemente da prática. A tendência no sentido de uma minimização da competência legislativa pode ser verificada em função da aceleração exponencial da conclusão de acordos executivos (item 2.1.2, a seguir). Se não é possível extrair do texto constitucional tais atos internacionais concluídos sob a égide de acordos executivos, deve-se recorrer à prática estatal para constatar a evolução do direito.

\section{2. i. i A repartição de competências entre o Poder Executivo e o Legislativo}

A primeira constituição escrita de 1791 conferiu papel importante ao corpo legislativo. Na qualidade de representante da nação, o corpo legislativo, eleito pelo povo (título III, artigo 2), era competente para ratificar tratados de paz, de aliança e de comércio (título III, capítulo III, seção primeira, artigo 3). A liberdade do rei para decidir e assinar tratados internacionais com as potências estrangeiras estava submetida à ratificação do corpo legislativo (título III, capítulo IV, seção III, artigo 3). A Revolução Francesa, bem como a introdução do regime parlamentar na Europa no século XIX transformaram a lógica aplicável à conclusão de tratados internacionais 
(MIRKINE-GUETZÉVITCH, 1931, p. 361; CACHAPUZ DE MEDEIROS, 1983, p. 31), introduzindo o elemento democrático (VISSCHER, 1952, p. 535). Quase todos os textos constitucionais democráticos conferiram ao Poder Legislativo uma participação importante na conclusão dos atos internacionais (ARAÚUJO, 1958, p. 148). A participação do Parlamento tornou-se uma condição, apesar das críticas que essa prática certamente suscitou (ROUSSEAU, 1846, p. 147). O regime parlamentar enquadrou a autonomia do governo, exigindo que este submetesse todo e qualquer tratado capaz de acarretar encargos financeiros no momento de sua execução à aprovação da Câmara. Essa fórmula permite efetuar uma distinção relativamente clara (MESTRE, 1931, p. 240-241) entre os tratados que comportam a intervenção das Câmaras e aqueles concluídos unicamente pelo Presidente da República.

A evolução constitucional da Europa e a participação do Poder Executivo e do Legislativo na conclusão de tratados internacionais foram igualmente marcadas pela adoção da Constituição belga de 1831. Trata-se de um texto constitucional inovador, cuja fórmula foi reproduzida em escala mundial (MIRKINE-GUETZÉVITCH, 1931, p. 365). São previstos dois tipos de tratados: aqueles que poderiam ser concluídos diretamente pelo Poder Executivo e aqueles que, relacionados ao comércio, às finanças do Estado e à legislação em vigor, eram obrigatoriamente submetidos à aprovação parlamentar. Não restam dúvidas de que a Constituição belga efetivamente serviu de modelo ao movimento constitucional no sentido de ampliar os poderes e as prerrogativas do Parlamento em matéria de conclusão de tratados internacionais presente em diversos países (MIRKINE-GUETZÉVITCH, 1931, p. 365-366). Segundo VISSCHER (1952, p. 535), esta evolução em matéria de tratados internacionais é um fato constitucional. Isso porque, na maioria dos Estados, as constituições submetem à aprovação parlamentar categorias cada vez mais numerosas de tratados internacionais.

Assim, a repartição de competências entre o Executivo e o Legislativo constitui regra na maior parte dos Estados (ROUSSEAU, 1987, p. 36). A participação do Poder Legislativo depende do regime de governo dos Estados: os europeus adotaram o regime parlamentar e os americanos optaram pelo regime presidencial (BURDEAU; HAMON; TROPER, 2007, p. 113 e 119). Os países dotados de regime parlamentar costumam seguir a fórmula franco-belga. O texto belga de 1831, que serviu de modelo durante a segunda metade do século XIX para diversas constituições europeias (ROUSSEAU, 1987, p. 37), prescreve a intervenção parlamentar seja para todos os tratados internacionais, seja para aqueles considerados como particularmente importantes. A França ${ }^{19}$ e a Inglaterra aplicam a segunda solução, que atualmente se afigura como a mais aceita (ROUSSEAU, 1987, p. 37).

As primeiras Constituições brasileiras seguiram o modelo franco-belga de uma competência conjunta entre o Poder Executivo e o Legislativo, seja submetendo os tratados considerados mais importantes à aprovação legislativa, seja generalizando a regra exigindo o assentimento do Legislativo para todo e qualquer tratado assinado 
pelo país. A Constituição de 1988 modificou a lógica anterior por meio da introdução de uma cláusula que deixa margem à discricionariedade do Poder Executivo, autorizando-o a não submeter ao Congresso Nacional os tratados que não acarretam compromissos gravosos ao patrimônio nacional, conforme será visto em seguida.

\section{2. i.2 A tendência de esvaziamento da COMpetência do Poder Legislativo}

Os acordos executivos desenvolveram-se consideravelmente na prática norte-americana. Nos Estados Unidos, o regime presidencial é caracterizado pela competência do Executivo com a intervenção obrigatória da Câmara alta para todos os tratados, nos termos do artigo 2, seção 2, da Constituição federal, de 17 de setembro de Constituição de 1787 prevê, em matéria de conclusão de tratados internacionais, uma repartição de competências entre o Presidente que negocia e o Senado que aprova por maioria de dois terços. O sistema americano de conclusão de tratados dificultou ou mesmo impossibilitou a ratificação de determinados tratados considerados de extrema importância (CARREAU, 2007, p. 130), como o Tratado de Versalhes que instituiu a Sociedade das Nações (SDN). Tal tratado, que contém em seu âmbito o pacto da SDN, nasceu do projeto dos quatorze pontos propostos pelo presidente americano Woodrow Wilson. A aprovação do tratado fracassou em função da não obtenção do acordo de dois terços dos senadores, conforme exige a constituição norte-americana.

O fracasso na aprovação legislativa do referido tratado despertou a opinião publica norte-americana com relação à rigidez do procedimento constitucional de conclusão de tratados internacionais praticado no país (VISSCHER, 1952, p. 538). A dificuldade de obter o consentimento dos senadores, conforme exige a constituição norte-americana, incentivou o Poder Executivo a recorrer à técnica dos executive agreements ou acordos em forma simplificada. Tais acordos distinguem-se, apenas teoricamente, dos treaties, estes últimos sendo considerados tratados no sentido formal. Os acordos executivos, como a própria denominação já pressupõe, são concluídos unicamente pelo Presidente sem a participação do Senado. Não restam dúvidas de que a consagração de tal prática reforça os poderes do Poder Executivo em matéria de política externa, não havendo significativa oposição do Congresso ou da Corte Suprema (CARREAU, 2007, p. 130 e 132). Ora, o Senado houve por bem tolerar o desenvolvimento desses acordos, em detrimento do risco de uma revisão constitucional capaz de limitar seus poderes, devidamente sustentada pela opinião publica (VISSCHER, 1952, p. 538). No que tange à Corte Suprema, esta efetivamente legalizou a prática, ${ }^{20}$ tendo admitido a conclusão de acordos executivos em determinados casos. ${ }^{21}$

A rigidez do regime norte-americano de conclusão de tratados internacionais, cujo objetivo era de democratizar o treaty-making power, não apenas levou à consagração da prática constitucional dos executive agreements, mas sobretudo à sua multiplicação. A tendência da conclusão de acordos em forma simplificada estendeuse em direção à maioria dos Estados dotados de um regime democrático, uma vez 
que o "procedimento quase legislativo" de aprovação de tratados internacionais tornou-se excessivamente lento e não adaptado à evolução da sociedade internacional (VISSCHER, 1952, p. 536-540). O texto constitucional norte-americano de 1787 foi objeto de diversas interpretações jurisprudenciais e doutrinárias divergentes, o que contribuiu para influenciar os legisladores brasileiros de 1891.

\subsection{A CONSAGRAÇão dos ACORdoS EM FORMA SIMPLIFICAdA NO BRASIL}

As Constituições brasileiras muito evoluíram com relação ao treaty making power. A Constituição política do Império do Brasil, de 25 de março de 1824, seguiu o modelo franco-belga, segundo o qual a intervenção do Poder Legislativo é obrigatória para alguns tratados considerados particularmente importantes, como aqueles que tratam da cessão ou mutação do território do Império ou de possessões do Império. ${ }^{22}$ Bueno (1978, p.66), jurista que bem interpretou a Constituição do Império, admite que a tarefa de concluir tratados internacionais é de competência do Poder Executivo por razões práticas, porém esse papel deveria ser atribuído, pelo menos na teoria, ao Poder Legislativo, pois constitui um ato de soberania ou uma expressão do voto nacional que produz efeitos com relação ao país. Entretanto, diversos textos constitucionais das monarquias liberais atenuaram o poder parlamentar na conclusão dos tratados internacionais, permitindo que este último fosse apenas informado dos atos concluídos pelo Executivo. É exatamente o que ocorreu na Carta Constitucional brasileira de 1824, que obrigou o Poder Executivo a informar o Legislativo acerca da conclusão de tratados específicos, caso o interesse e a segurança do Estado assim o permitissem (ARAÚJO, 1958, p. 148). Todavia, os ministros não devem exercer suas competências em matéria de conclusão de tratados internacionais com excesso de poder, pois o Legislativo dispõe não somente o poder de ser informado, mas sobretudo de controlar as atividades executivas (MESTRE, 1931, p. 245). Caso o Poder Executivo exerça suas funções violando as atribuições constitucionais, o Legislativo poderá rejeitar o tratado por ele concluído. A aprovação legislativa somente será exigida no caso de tratados que exigem a cessão ou a troca de territórios do Império ou de possessões do Império em tempos de paz (BUENO, 1978, p. 66).

A partir da primeira Constituição brasileira da República de 1891, o poder de concluir tratados passou a ser obrigatoriamente dividido entre o chefe do Poder Executivo e o Congresso Nacional (CACHAPUZ DE MEDEIROS, 1995, p. 118). Tal exigência foi introduzida com a finalidade de evitar que os tratados que acarretassem encargos ao patrimônio nacional fossem concluídos unicamente pelo Executivo, situação que era frequente durante o Império. Foram apresentados diversos projetos para a primeira Constituição republicana (CACHAPUZ DE MEDEIROS, 1995, p.112-117 e RIBEIRO,1917, p.91-96), sendo que diversos deles divergiam no que tange à exigência de uma aprovação legislativa para todos os tratados. O projeto que foi adotado com algumas modificações foi aquele apresentado por Magalhães Castro, 
que condicionava a conclusão de tratados pelo Presidente da República ao referendo do Congresso Nacional. A fórmula ad referendum, ${ }^{23}$ introduzida no primeiro texto constitucional republicano, significa que compete definitivamente ao Congresso a conclusão de tratados e de convenções assinadas pelo presidente. A competência de “dispor/decidir definitivamente" sobre os tratados, acordos ou atos internacionais é prevista igualmente na Constituição atual, apesar de ser flagrantemente inadequada. Com efeito, a decisão definitiva caberia ao Presidente da República, pois este é livre para ratificar os tratados internacionais após sua aprovação pelo Poder Legislativo brasileiro. ${ }^{24}$ Assim sendo, em não havendo oposição congressual à conclusão de um tratado internacional, ${ }^{25}$ a decisão definitiva caberá efetivamente ao chefe de Estado.

Uma análise dos textos constitucionais brasileiros permite concluir que todas as constituições posteriores, na linha da Constituição de 1891, mantiveram a participação obrigatória do Poder Legislativo na conclusão dos tratados internacionais em função dos imperativos democráticos (MIRANDA, 1967, p. 326), por meio da fórmula ad referendum. Entretanto, tal regra foi substancialmente modificada com a adoção do Texto Constitucional de 1988, que modificou as regras relativas ao treaty making power ${ }^{26}$ previstas nas Constituições anteriores. Foi introduzido um elemento distintivo aos tratados que deverão obrigatoriamente ser submetidos ao Congresso Nacional, sem que tal fato signifique um aumento das prerrogativas do Legislativo. $\mathrm{O}$ presidente possui competência exclusiva para negociar e concluir acordos internacionais, sendo tal poder delegado aos plenipotenciários (CARREAU, 2007, p. 125), nos termos do artigo 7 da Convenção de Viena sobre direito dos tratados. No Brasil, país que segue a prática internacional em matéria de conclusão de tratados internacionais, os ministros do Ministério das Relações Exteriores (MRE) gozam de presunção de representatividade, não devendo apresentar carta de plenos poderes (MELLO, 1997, p. 195).

A imprecisão do artigo $84^{27}$ poderia fazer supor que o Poder Executivo deveria encaminhar todos os tratados internacionais regularmente firmados ao Congresso Nacional, na mesma linha do texto constitucional de 1891. Entretanto, o artigo 49 busca elucidar quais tratados efetivamente exigirão uma aprovação do Poder Legislativo. ${ }^{28}$ A evolução das relações internacionais, o aumento do número de acordos internacionais e de sua urgência, bem como a conclusão de acordos considerados de menor importância contribuíram para que a obrigação geral de submissão de tratados e convenções internacionais ao Poder Legislativo fosse atenuada, o que constitui tendência no direito constitucional moderno (ARAÚJO, 1958, p. 149). Nos termos do artigo 49 da Constituição Federal, a competência do Congresso Nacional é restrita aos tratados que acarretam compromissos gravosos ao patrimônio nacional. Os artigos 84 e 49 constituem as únicas disposições constitucionais que tratam da conclusão e incorporação dos tratados no ordenamento jurídico brasileiro (CANÇADO TRINDADE, 2006A, p. 141), tendo sido severamente criticados pelos juristas brasileiros (FERREIRA 
FILHO, 1992, p. 21; SETTE CAMARA, 69/71:74, 1987/1989; MELLO, 1994, p. 277). O legislador optou pela menção acerca dos "compromissos gravosos ao patrimônio nacional" com o objetivo de abarcar os acordos de caráter econômico e financeiro que poderiam comprometer o patrimônio nacional. Tratava-se dos acordos e compromissos concluídos pelo governo com o FMI, com o BIRD e com o Clube de Paris (CACHAPUZ DE MEDEIROS, 1995, p. 177-188 e p. 385).

Não restam dúvidas de que o legislador teve a intenção de limitar a margem de manobra do Poder Executivo por meio da submissão obrigatória ao Congresso de acordos concluídos na área financeira. Entretanto, um resultado totalmente oposto foi atingido, pois o Poder Executivo beneficiou-se amplamente de tal autorização constitucional (SETTE CAMARA, 1987/1989, p. 73). Segundo Cachapuz de Medeiros, a Constituição de 1988 perdeu a oportunidade de esclarecer as regras relativas ao treaty making power e manteve a dualidade doutrinária: alguns sustentavam que todos os acordos deveriam obrigatoriamente ser submetidos ao Poder Legislativo, sendo que outros insistiam na possibilidade da conclusão de acordos executivos (CACHAPUZ DE MEDEIROS, 1995, p. 383). A primeira tendência, que permite a conclusão de certos acordos sem intervenção legislativa, foi concretizada na prática diplomática brasileira.

A análise com o objetivo de avaliar o conteúdo e a natureza do tratado internacional será efetuada pelo MRE, em momento anterior ao envio deste ao Congresso Nacional. O Executivo verificará, na ocasião, se o tratado é capaz de produzir compromissos gravosos ao patrimônio nacional ou, ainda, se pode se enquadrar no domínio reservado à lei. A liberdade da ação do Poder Executivo na matéria tende a ser ilimitada, podendo este optar pela não submissão de um tratado à aprovação do Congresso, contrariamente ao referido dispositivo constitucional. Uma leitura conjunta dos artigos 49, inciso I e 84, inciso VIII da Constituição brasileira leva a crer que alguns tratados internacionais não devem, obrigatoriamente, ser submetidos ao Poder Legislativo. Ora, apesar de parecer evidente, essa interpretação dividiu sobremaneira a doutrina brasileira, que interpretou de forma divergente o conteúdo dos referidos artigos. Os debates em torno da questão foram bastante positivos para esclarecer e preencher as lacunas da prática constitucional brasileira em matéria de incorporação de tratados internacionais. Ademais, a prática diplomática brasileira houve por bem reconhecer outros critérios aplicáveis à incorporação dos tratados internacionais, elucidando a imprecisão do dispositivo constitucional.

Com efeito, durante as revisões constitucionais posteriores, surgiu intenso debate entre os internacionalistas brasileiros, cujas opiniões divergiam no que tange à obrigatoriedade de uma intervenção legislativa para todos os tratados internacionais assinados pelos representantes do país. A origem de tal discurso remonta à entrada em vigor da Constituição de 1946, com o artigo de Accioly (1948) e a respectiva resposta de Valladão (1950). ${ }^{29}$ Posteriormente, o MRE adotou posição favorável ao 
reconhecimento da prática dos acordos executivos como um reflexo das relações internacionais contemporâneas, confirmando a tese de Accioly (1948).

Carneiro (2000), consultor jurídico do Ministério, confirmou a possibilidade de conclusão de acordos não submetidos ao Poder Legislativo nas situações mencionadas por Accioly (1948). Em seu parecer pronunciado em 1950, o consultor admitiu exceções à suposta regra da intervenção legislativa, que englobam os acordos relativos a assuntos de competência privativa do Poder Executivo; os acordos concluídos para a execução, aplicação ou esclarecimento de uma matéria de importância secundária de um tratado; e os acordos de prorrogação ou modificação de um acordo executivo ainda em vigor (CARNEIRO, 2000, p. 401-414). Diversos autores e consultores jurídicos do Itamaraty (ROCHA, 1968, p. 175-183; CANÇADO TRINDADE, 2006A p. 518-523) confirmaram a tese de Accioly (1948), assim como o fez o atual consultor jurídico do MRE desde 1998, Cachapuz de Medeiros (1995). Este último afirma que tais acordos podem ser concluídos sem a aprovação do Congresso nas seguintes situações:

1) quando se destinem a executar, interpretar ou prorrogar tratados preexistentes devidamente aprovados pelo legislativo; 2) quando forem estritamente inerentes à rotina diplomática ordinária e puderem ser desconstituídos mediante comunicação à outra parte, eficaz desde logo, sem necessidade de renúncia (CACHAPUZ DE MEDEIROS, 1995, p. 481).

O consultor sugere a utilização da fórmula acima no processo de conclusão de tratados internacionais, pois melhor se ajustaria às necessidades da vida internacional contemporânea, respeitando, ademais, as prescrições da Constituição Federal de 1988. Segundo o consultor jurídico, 317 acordos em forma simplificada foram concluídos pelo Governo brasileiro sem intervenção do Congresso Nacional entre 1946 e 1981 (CACHAPUZ DE MEDEIROS, 1995, p. 136-145). Esse número continua aumentando consideravelmente, conforme é possível inferir da quantidade de acordos executivos concluídos entre 5 de outubro de 1988, data da entrada em vigor da Constituição de 1988, e 31 de dezembro de 1993. É possível contabilizar cerca de 180 acordos em forma simplificada, sendo que a maioria constitui ajustes complementares a tratados preexistentes (CACHAPUZ DE MEDEIROS, 1995, p. 431).

A divisão de atos internacionais do MRE publicou, em 1984, seu manual de procedimentos relativos à prática diplomática brasileira em matéria de conclusão de atos internacionais (MINISTÉRIO DAS RELAÇÕES EXTERIORES, 1984, 45 p.). Em razão da multiplicação dos atos internacionais concluídos pelo Brasil desde a publicação do primeiro manual, o que representa cerca de 300 por ano, a divisão de atos internacionais houve por bem reeditar tal documento em 2008. O MRE confirma, portanto, a tese segundo a qual alguns tratados não exigem aprovação legislativa. Trata-se 
dos tratados concluídos por meio de troca de notas ou outro formato que tenham sido autorizados ou constituam execução de outro anterior, devidamente aprovado e que não o modifique (MINISTÉRIO DAS RELAÇÕES EXTERIORES, 2008, p. 16). Estes atos são “considerados pela doutrina como derivados da 'diplomacia ordinária' ou rotineira”. Não restam dúvidas quanto ao reconhecimento da prática reiterada dos acordos em forma simplificada pelo Poder Executivo brasileiro, formando um verdadeiro costume (SETTE CAMARA, 1987/1989, p. 66; CANÇADO TRINDADE, 2006A, p. 87). O reconhecimento da prática dos acordos executivos no Brasil, na esteira dos Estados Unidos e da Europa, conduz à constatação no sentido de que a assinatura não produz somente a obrigação de boa-fé, prevista no artigo 18 da Convenção de Viena, conforme aplicável aos acordos em forma solene. No caso dos acordos em forma simplificada ou executivos, a assinatura já é suficiente para sujeitar o Estado às regras do tratado, cujo descumprimento ensejaria responsabilização internacional.

\section{Conclusão}

A discussão acerca dos efeitos da assinatura para o Estado perante o direito internacional não se restringe à ótica puramente interna ou internacional. Embora os Estados tenham optado pela limitação das obrigações previstas na Convenção de Viena sobre o Direito dos Tratados, eliminando a obrigatoriedade de submissão de um tratado internacional ao órgão interno competente, como pretendia Lauterpacht, não se pode negar que a assinatura não é uma simples formalidade acessória no processo de celebração de tratados internacionais. A assertiva se aplica tanto aos acordos em forma simplificada quanto aos acordos em forma solene. Nestes últimos, a assinatura pressupõe que o Estado aceita os termos do tratado, indicando a probabilidade de ratificação. Não se trata de um ato sem consequências, pois faz nascer uma esperança legítima nos demais Estados signatários contratantes, assim como nos indivíduos envolvidos. Por este motivo, a decisão do Estado de não mais se tornar parte de um tratado deve ser criteriosa e justificada, conforme previam os debates prévios ao artigo 18 da Convenção de Viena de 1969. Com efeito, a discricionariedade quanto à ratificação não configura arbitrariedade estatal de forma a permitir toda sorte de comportamento contrário ao direito internacional.

Conforme já apontado, a razão de ser da ratificação é a necessidade de aprovação legislativa, que constitui atualmente "fato constitucional" previsto na maior parte das constituições modernas como uma resposta ao imperativo de democratização das relações internacionais (VISSCHER, 1952, p. 535). A necessidade de associar o Poder Legislativo na conclusão de atos internacionais mostrou descompasso entre o respeito das regras constitucionais e as exigências do direito internacional. Com efeito, alguns Estados corriam o risco de se expor negativamente perante a comunidade internacional por fato atribuído ao Poder Legislativo no momento da aprovação ou 
rejeição do tratado que lhe foi submetido, abalando a confiança legítima que os demais Estados participantes lhe depositaram quando da assinatura. Evidentemente que o atraso ou a negativa da ratificação não poderá ser atribuído unicamente ao Poder Legislativo, já que não há qualquer obrigação ou prazo de remissão do tratado ao Poder Legislativo aceito como costume internacional, assim como também não há qualquer obrigatoriedade de ratificação após a devida aprovação pelo Legislativo. Feitas as cabíveis observações, o Poder Executivo, utilizando-se da justificativa de dar conta dos compromissos internacionais, evitando a ratificação tardia de atos internacionais, houve por bem incorporar a prática dos executive agreements que ganharam força na prática norte-americana. O Brasil, assim como os demais Estados democráticos, considerou que o procedimento "quase legislativo" utilizado na aprovação legislativa dos tratados internacionais apenas poderia ser justificado em momento no qual os tratados internacionais constituíam exceção, relacionando-se principalmente às matérias de grande importância política ou atinentes à natureza legislativa (VISSCHER, 1952, p. 536). Ora, atualmente a maior parte dos tratados internacionais é concluída seguindo o trâmite dos acordos em forma simplificada, ou seja, excluindo-se a participação do Poder Legislativo e, consequentemente, a exigência de ratificação.

O surgimento da prática dos acordos executivos reforça a tendência de se atribuir importância crescente à assinatura, que passa a constituir a principal forma de sujeição de um Estado a um tratado internacional. Por este motivo, é essencial reconhecer os efeitos decorrentes da assinatura de um tratado, seja ele concluído sob a forma solene ou abreviada. Mesmo nos tratados em forma solene, que somente se aperfeiçoam com a ratificação, os nacionais de um Estado signatário contratante poderão exigir, na qualidade de sujeitos de direito internacional, a adoção de um comportamento condizente com as obrigações assumidas na ótica internacional, que, muitas vezes, são fruto de costume internacionalmente reconhecido, além de constar expressamente dos tratados eventualmente assinados. Independentemente da discussão acerca de outras fontes de direito internacional, nas quais poderiam ser incluídos o costume e a noção de jus cogens, qualquer Estado, por meio de seus Poderes Executivo e Legislativo, deverá atentar para os efeitos de seus atos perante os demais participantes e seus nacionais, entendendo que a adoção de um comportamento coerente contribui essencialmente para sua imagem e credibilidade no cenário interno e internacional.

: ARTIGO APROVADO (15/05/2013) : RECEBIDO EM 05/05/2012 


\section{NOTAS}

1 Trata-se dos tratados internacionais que determinam que o consentimento em obrigar-se é operado por meio da ratificação. Vide artigo 11, Convenção de Viena sobre o Direito dos Tratados de 26 de maio de 1969, em vigor em 27 de janeiro de 1980 .

2 Gerald Fitzmaurice, relator sobre Direito dos Tratados da Comissão de Direito Internacional da Organização das Nações Unidas de 1960, ressalta que a palavra "tratado" pode ser usada em dois sentidos, seja como documento, isto é, como o texto resultante das negociações, seja como acordo em si. Desta forma, até a sua entrada em vigor, o tratado tem o status de texto, somente depois é que passa a adquirir o status de acordo legal (ORGANIZAÇÃO DAS NAÇÕES UNIDAS. Comissão de Direito Internacional. Yearbook of the International Law Commission. V. II. Fitzmaurice, G. Law of Treaties Document A./CN.4/101, 1956, p. 121).

3 Segundo Visscher, atualmente, é possível afirmar que não há distinção material entre o tratado e o acordo em forma simplificada, pois a escolha entre ambos reside unicamente em razões de tática política (1952, p. 539).

4 As quatro fases da celebração de um tratado, que podem ser simultaneamente implementadas, são as seguintes: (i) adoção e autenticação do texto; (ii) conclusão do tratado; (iii) sujeição dos Estados às regras do tratado; e (iv) entrada em vigor do tratado. As quatro fases mencionadas estavam assim previstas no $\S 4$ do artigo 14 na proposta de Código do Direito dos Tratados presente no Relatório de Gerald Fitzmaurice apresentado na $8^{\text {a }}$ Sessão da Comissão de Direito Internacional da Organização das Nações Unidas realizada em 1956 (ORGANIZAÇÃO DAS NAÇÕES UNIDAS. Comissão de Direito Internacional. Yearbook of the International Law Commission. V. II. Fitzmaurice, G. Law of Treaties Document A./CN.4/101, 1956, p. 110). Embora este artigo não tenha sido incluído no texto final do tratado, estas fases podem ser identificadas pela leitura da Seção 1 - Conclusão de Tratados - e da Seção 3 Entrada em Vigor dos Tratados e Aplicação Provisória - da Parte II - Conclusão e Entrada em Vigor de Tratados - da Convenção de Viena sobre o Direito dos Tratados.

5 Nos termos do referido artigo, "Um Estado é obrigado a abster-se da prática de atos que frustrariam o objeto e a finalidade de um tratado, quando: a) tiver assinado ou trocado instrumentos constitutivos do tratado, sob reserva de ratificação, aceitação ou aprovação, enquanto não tiver manifestado sua intenção de não se tornar parte no tratado".

6 O Estado contratante tem o direito de "fazer objeções às reservas formulados por outros Estados como sublinhou a C.I.J. em parecer relativo às Reservas à Convenção sobre o genocídio” (DINH; DAILLIER; PELLET, 2003, p. 138).

7 Alguns exemplos podem ser citados como a recusa da França em ratificar a Convenção de 20 de dezembro de 1841 sobre a repressão e o comércio de escravos e o tratado de 27 de maio de 1952 que instituiu a Comunidade Europeia de Defesa; a recusa dos EUA em ratificar a Carta de Havana de 1948, o tratado SALTI de 1979 com a URSS e, até mesmo, o Pacto da Sociedade das Nações, embora o presidente estadunidense, Wilson, fosse o principal responsável por ele.

8 Um exemplo que abarca as duas situações é o do Brasil em relação à própria Convenção de Viena sobre o Direito dos Tratados, assinada em maio de 1969 pelo Executivo, foi entregue para o exame do Legislativo em abril de 1992, pelo, então, Presidente Fernando Collor. Foi aprovada, finalmente, pela Câmara dos Deputados em maio de 2009 e encaminhada ao Senado que a aprovou foi devolvida ao Executivo que a ratificou em setembro e a promulgou em dezembro do mesmo ano. Ao todo, a Convenção permaneceu 23 anos no Executivo e 17 anos no Legislativo.

9 Para alguns exemplos acerca do largo período decorrido entre a assinatura e a ratificação de tratados internacionais na França, vide DINH; DAILLIER; PELLET, 2003, p. 143. No que tange ao Brasil, é possível citar o Estatuto da Conferência de Haia sobre Direito Internacional Privado assinado pelo Brasil em 1951 e ratificado em 2001 e o Protocolo de Genebra sobre a Proibição de Emprego na Guerra de Gases Asfixiantes, Tóxicos ou Similares e de Meios Bacteriológicos assinado pelo Brasil em 1925 e ratificado em 1970.

10 CORTE PERMANEnTE DE JUSTIÇA INTERnACIOnAL. Certos Interesses Alemães na Alta Silésia Polaca. Decisão de 25 de maio de 1926. Este caso é referência para os casos de obrigação de não privar um tratado de seu objeto e finalidade. Ver também: ONU. Comissão de Direito Internacional. Yearbook of the International Law Commission. Vol. II. LAUTERPACHT, H. Law of Treaties Document A/CN.4/63, 1953, p. 110; DINH; DAILLIER; PELLET, 2003 , p. 144. 
11 Vide artigo 5, alínea 2 (ONU, 1953, p. 108).

12 Os tratados normativos estão em consonância com a percepção de um novo direito internacional, que reconhece como seus sujeitos não somente os Estados e as organizações internacionais, mas também as organizações não governamentais, as empresas transnacionais e a pessoa humana. Neste sentido, ver CANÇADO TRINDADE, A. A., 2006; JEAN-ARNAUD, 2007.

13 KLABBERS (2001, p. 4-8) considera a situação hipotética na qual um Estado assina uma convenção contra a tortura, mas antes da ratificação pratica um ato de tortura e suas respectivas consequências.

14 O teste subjetivo também apresenta falhas. Para uma análise acerca do círculo vicioso, no qual a validação do teste das expectativas legítimas é feita por meio do teste de intenções e vice-versa (KLABBERS, 2001, P.9).

15 A carta foi enviada nos seguintes termos: "Dear Mr. Secretary-General: This is to inform you, in connection with the Rome Statute of the International Criminal Court adopted on July 17, 1998, that the does not intend to become a party to the treaty. Accordingly, the has no legal obligations arising from its signature on. The requests that its intention not to become a party, as expressed in this letter, be reflected in the depositary's status lists relating to this treaty. Sincerely, S/John Bolton”.

16 Os EUA iniciaram negociações com outros Estados para a celebração de tratados bilaterais, nos quais estes Estados assumiam o compromisso de que, mesmo fazendo parte do Tribunal Penal Internacional, não entregariam nacionais estadunidenses. Há discussão acerca da efetiva violação da obrigação interina pelo governo estadunidense, já que o próprio Tratado de Roma (artigo 98, § 2), referente à cooperação relativa à renúncia, à imunidade e ao consentimento na entrega previu a possibilidade de celebração deste tipo de tratado mesmo entre os Estados partes.

17 O principal objeto deste artigo não é o ato internacional de retirada da assinatura, mas o poder do Presidente de fazer isso enquanto o tratado está com o Senado, como foi o caso do Tratado Compreensivo de Banimento dos Testes Nucleares. O Presidente Bush tinha a intenção de retirar também a assinatura deste tratado, mas ele se encontrava com o Senado que se recusou a entregá-lo para o Presidente.

18 Nos termos do artigo 11, da Convenção de Viena sobre o direito dos tratados de 1969: “O consentimento de um Estado em obrigar-se por um tratado pode manifestar-se pela assinatura, troca dos instrumentos constitutivos do tratado, ratificação, aceitação, aprovação ou adesão, ou por quaisquer outros meios, se assim acordado”.

19 O artigo 8 da lei constitucional francesa de 1875 consagrava a repartição de competências entre o Executivo e o Legislativo, associando este último à aprovação de certos tratados bem definidos pelo texto constitucional. A exigência de ratificação de tratados mais importantes foi mantida igualmente no artigo 27 da Constituição de 27 de outubro de 1946, que ampliou as situações nas quais o Parlamento participava do processo de ratificação dos tratados, acrescentando outros tratados à lista daqueles submetidos a uma intervenção legislativa (VEDEL, G. Manuel élémentaire de droit constitutionnel. Paris: Librairie du Recueil Sirey, 2002, p. 527).

20 U.S. v. Belmont 301 U.S. 324, 1937, Clunet 1938.453 et 569, et U.S. v. Pink 315 U.S. 203, 1942, Clunet 1940-1945.75. No caso U.S v. Belmont, a Corte considerou que certos tratados não são obrigatoriamente submetidos ao Congresso.

21 Para mais detalhes acerca do domínio coberto pelos acordos executivos, vide ROUSSEAU, 1970, p. 37-38 e CARREAU, 2007, p. 131.

22 Vide o artigo 102 da Constituição do Império, relativo às atribuições do Imperador como chefe do Poder Executivo.

23 O legislador optou pela fórmula ad referendum, que supõe uma autorização prévia do Congresso Nacional para que o presidente possa concluir atos internacionais (FRANCO, A. A. M. Estudos de Direito Constitucional. Rio de Janeiro: Forense, 1957, p. 263).

24 Em seus comentários à Constituição de 1967, com a emenda de 1969, Ferreira Filho afirmou que o Congresso Nacional dispunha da palavra final no que tange à conclusão dos tratados internacionais (Comentários à Constituição Brasileira. $6^{\text {a }}$ ed. São Paulo: Saraiva, 1986, p. 247). 
25 Entretanto, se o Congresso Nacional decidir não aprovar um tratado internacional, tal decisão é definitiva e impede qualquer atuação em sentido contrário do Presidente da República. Vide CACHAPUZ DE MEDEIROS, 1995, p. 118.

26 A primeira ideia de "treaty making power" remonta a VATTEL, E. Le droit des gens ou principes de la loi naturelle appliquées à la conduite et aux affaires des nations et des souverains. V. 3. Washington: The Carnegie Institution, 1916, p. 160. Todavia, um dos primeiros juristas a empregar tal expressão foi Wheaton, quando afirmava que "o poder de concluir tratados depende da constituição civil de cada Estado". No original, "the treaty making power dependent on the municipal Constitution”, in Eléments de droit international. Paris: A. Durand, 1848, t. 1, p. 227.

27 Segundo o artigo 84 da Constituição de 1988, “Compete privativamente ao Presidente da República: (...) VIII - celebrar tratados, convenções e atos internacionais, sujeitos a referendo do Congresso Nacional; (...)”.

28 Vide artigo 49, I, da Constituição de 1988. Segundo Bastos, o objetivo do Texto Constitucional de 1988 era de restringir a possibilidade de concluir acordos executivos, evitando assim toda sorte de abuso (2002, p. 112).

29 O debate relativamente à conclusão de acordos executivos tem origem na entrada em vigor da Constituição de 1946, com o artigo de Accioly (1948, p. 5-11), que defende a possibilidade da conclusão de acordos em forma simplificada no Brasil. Seguindo essa linha, o Brasil poderia se obrigar internacionalmente sem necessidade de obter autorização legislativa, sobretudo em função da competência privativa dos órgãos constitucionais (ACCIOLY, 1948, p. 7). Dois anos após a publicação do artigo de Accioly, Valladão expôs sua tese no mesmo Boletim da Sociedade Brasileira de Direito Internacional, contestando os argumentos que sustentavam a possibilidade da conclusão de acordos executivos em determinados casos (VALLADÃO, 1950, p. 95-108). A resposta de Accioly combatendo os argumentos de Valladão foi publicada no número seguinte do referido boletim em 1951 (ACCIOLY, 1951, p. 20-33). Posteriormente, Valladão reconsiderou sua tese em parecer publicado em 1969 (VALLADÃO, 1969, p. 111-112).

\section{REFERÊNCIAS BIBLIOGRÁFICAS}

\section{Livros}

ARAúJO, João Hermes Pereira de. A processualística dos atos internacionais. Rio de Janeiro: Ministério das Relações Exteriores, 1958.

BASTOS, Celso Ribeiro; MARTINS, Yves Gandra. Comentários à Constituição do Brasil. 3. ed. São Paulo: Saraiva, 2002, 4. v., t. 1, artigos 44-69.

BUENO, José Antônio Pimenta. Direito Público Brasileiro e Análise da Constituição do Império. Brasília: Senado Federal, 1978, p. 66

BURDEAU, Georges; HAMON, Francis; TROPER, Michel. Droit constitutionnel. 30 éd. Paris: L.G.D.J., 2007.

CACHAPUZ DE MEDEIROS, Antônio Paulo. O Poder Legislativo e os tratados internacionais. Porto Alegre: LPM, 1983 O poder de celebrar tratados: Competência dos poderes constituídos para a celebração dos tratados à luz do direito internacional, do direito comparado e do direito constitucional brasileiro. Porto Alegre: Sergio Antonio Fabris Editor, 1995.

CANÇADO TRINDADE, Otávio Augusto Drummond. O Mercosul no direito brasileiro, incorporação de normas e segurança jurídica. Belo Horizonte: Del Rey, 2006A.

CANÇADO TRINDADE, Antônio Augusto. A humanização do direito internacional. Belo Horizonte: Del Rey, $2006 \mathrm{~B}$. CARREAU, Dominique. Droit international. 9 éd. Paris: Pedone, 2007.

DINH, Nguyen Quoc; DAILlIER, Patrick; PELLET, Alain. Direito internacional público. 2. ed. Lisboa: Fundação Calouste Gulbenkian, 2003.

FERREIRA FILHO, Manoel Gonçalves. Comentários à Constituição brasileira. 6. ed. São Paulo: Saraiva, 1986. . Comentários à Constituição Brasileira de 1988. Vol. II. São Paulo: Saraiva, 1992.

. Do processo legislativo. 5. ed. São Paulo: Saraiva, 2002.

. Curso de direito constitucional. 29. ed. São Paulo: Saraiva, 2002.

FRANCO, Afonso Arinos de Melo. Estudos de Direito Constitucional. Rio de Janeiro: Forense, 1957.

JEAN-ARNAUD, André. Governar sem fronteiras: entre globalização e pós-globalização. Rio de Janeiro: Lumen Juris, 2007. 
LARENZ, Karl. Metodologia da ciência do direito. Lisboa: Fundação Calouste Gulbenkian, 1997.

MELLO, Celso de Albuquerque. Direito Constitucional Internacional. Rio de Janeiro: Renovar, 1994.

. Curso de direito internacional público. 11. ed. São Paulo: Saraiva, v. 1, 1997.

MIRANDA, Pontes de. Comentários à constituição de 1967. Tomo III. São Paulo: Revista dos Tribunais, 1967.

REUTER, Paul. Introduction au droit des traités. 3 éd. Paris : PUF, 1995.

. La convention de Vienne du 23 mai 1969 sur le droit des traités. A. Colin, 1970.

RIBEIRO, João Coelho Gomes. A gênese histórica da Constituição Federal. Oficina Grafica da Liga Maritma Brasileira, 1917.

ROUSSEAU, Jean-Jacques. Lettres écrites de la montagne. In: Euvres complètes de J.J. Rousseau. Tomme III, Paris: Bureau de la Société des Publications Illustres, 1846.

ROUSSEAU, Charles. Droit international public. 11ème ed. Paris: Dalloz, 1987.

SCELLE, Georges. Manuel de droit international public. Paris, 1948, p. 618.

VATTEL, Emer de. Le droit des gens ou principes de la loi naturelle appliquées à la conduite et aux affaires des nations et des souverains. V. 3. Washington: The Carnegie Institution, 1916. p. 160.

VEDEL, Georges. Manuel élémentaire de droit constitutionnel. Paris: Librairie du Recueil Sirey, 2002.

WHEATON, Henry. Eléments de droit international. Paris: A. Durand, 1848.

ZOLLER, Élisabeth. La bonne foi en droit international public. Paris: Pedone, Paris, 1977.

\section{Cursos da Academia de Direito Internacional da Haia}

BASDEVANT, Jules. La conclusion et la rédaction des traités et des instruments diplomatiques autres que les traités. In: R.C.A.D.I., v. 15, p. 539, 1926-V.

MESTRE, Achille. Les traités et le droit interne. In: R.C.A.D.I., 1931-IV.

MIRKINE-GUETZÉVITCH, Boris. Droit international et droit constitutionnel. In: R.C.A.D.I., p. 307-465, 1931-IV.

VISSCHER, Paul de. In: R.C.A.D.I., p. 511-578, 1952-I.

\section{Artigos}

ACCIOLY, Hildebrando. A ratificação e a promulgação dos tratados, em face da Constituição Federal Brasileira. Boletim da Sociedade Brasileira de Direito Internacional, Rio de Janeiro, IV, n. 7, p. 5-11, 1948. CANÇADO TRINDADE, Antônio Augusto. Ainda o problema da ratificação dos tratados, em face da Constituição Federal Brasileira. Boletim da Sociedade Brasileira de Direito Internacional, Rio de Janeiro, ano VII, n. 13-14, p. 20-33, jan./dez. 1951.

. Acordos internacionais: as atribuições distintas de negociação pelo Poder Executivo e de aprovação pelo Poder Legislativo. A questão da aprovação pelo Legislativo de atos internacionais; Processualística dos atos internacionais. Questão da aprovação parlamentar: princípio; alcance. Equilíbrio entre os Poderes; Participação do Legislativo na celebração de tratados. Acordos por troca de notas, acordos em forma simplificada. Ressalvas a atos internacionais em vigor. In: CACHAPUZ DE MEDEIROS, Antônio Paulo. (Org.). Pareceres dos consultores jurídicos do Itamaraty.. Brasília: Senado Federal, p. 463-465; p. 518-523; p. 527-531 e p. 518-523, 2004, v. VIII (1985-1990).

CARNEIRO, Levi. Acordos por troca de notas. Quando é necessária a aprovação pelo Congresso Nacional; Acordo mediante notas reversais para assegurar o cumprimento de tratado. Necessidade de ratificação pelo Congresso Nacional. In: CACHAPUZ DE MEDEIROS, A. P. (Org.) Pareceres dos consultores jurídicos do Itamaraty.. Brasília: Senado Federal, p. 401-414 e p. 117-118, 2000, v. IV (1946-1951).

COT, Jean-Pierre. La bonne foi et la conclusion des traités. Revue belge de droit international, 1968, p. 140. KLABBERS, Jan. How to defeat a treaty's object and purpose pending entry into force: toward manifest intent. Vanderbilt Journal of Transnational Law, Mar 1, 2001.

ROCHA, Augusto de Rezende. Acordos internacionais: quando é desnecessária a aprovação pelo Congresso Nacional. Boletim da Sociedade Brasileira de Direito Internacional, Rio de Janeiro, ano XXIV, n. 47-48, p. 175 183, jan./dez. 1968 .

SCOTT, David C. Presidential power to “un-sign” treaties. The University of Chicago Law Review. v. 69, n. 3, 2002. SETTE CAMARA, José. A conclusão dos tratados internacionais e o direito constitucional brasileiro. Boletim da Sociedade Brasileira de Direito Internacional, Brasília, XXXIX a XLI, n. 69/71, p. 56-75, 1987/1989.

VALLADÃO, Haroldo. Conceito moderno de ratificação dos tratados e convenções, democrático, originário do Direito Internacional americano. In: CACHAPUZ DE MEDEIROS, A. P. (Org.) Pareceres dos consultores jurídicos do Itamaraty.. Brasília: Senado Federal, 2002, v. VI (1961-1971).

. Aprovação de ajustes internacionais pelo Congresso Nacional. Boletim da Sociedade Brasileira de Direito Internacional, Rio de Janeiro, ano VI, n. 11-12, p. 95-108, jan./dez. 1950. 
Necessidade de aprovação pelo Congresso Nacional de acordo internacional. Boletim da Sociedade Brasileira de Direito Internacional, Rio de Janeiro, ano XXV, n. 49-50, p. 111-112, jan./dez. 1969.

\section{Comissão de Direito Internacional - Anuários da Comissão de Direito Internacional} (Disponíveis em http://www.un.org/law/ilc/)

ORGANIZATION OF THE UNITED NATIONS. Commission on International Law. Yearbook of the International Law Commission. V. II. LAUTERPACHT, Hersch. Law of Treaties Document A/CN.4/63, 1953. ORGANIZATION OF THE UNITED NATIONS. Commission on International Law. Yearbook of the International Law Commission. V. II. Fitzmaurice, George. Law of Treaties Document A./ CN.4/101, 1956. ORGANIZATION OF THE UNIETD NATIONS. Commission on International Law. Yearbook of the International Law Commission. V. I, 1965.

ORGANIZATION OF THE UNITED NATIONS. Commission on International Law. Yearbook of the International Law Commission. Vol. I, 1966, p. 326.

ORGANIZATION OF THE UNITED NATIONS. Conference on the Law of Treaties. Official Records. Documents of the Conference. Draft articles on the Law of treaties with commentaries, adopted by the International Law Commission at its eighteenth session, 1971.

\section{Ministério das Relações Exteriores}

MINISTÉRIO DAS RELAÇÕES EXTERIORES. Atos internacionais. Prática diplomática brasileira. Manual de procedimentos. Brasília: Departamento Consular e Jurídico/Divisão de Atos Internacionais do Ministério das Relações Exteriores, 1984.

MINISTÉRIO DAS RELAÇÕES EXTERIORES. Atos internacionais. Prática diplomática brasileira. Manual de procedimentos. Brasília: Departamento Consular e Jurídico/Divisão de Atos Internacionais do Ministério das Relações Exteriores, 2008.

\section{Paula Wojcikiewicz Almeida}

Praia de Botafogo, n. 190, $13^{\circ}$ andar Botafogo - 22250-040 Rio de Janeiro - RJ - Brasil paula.almeidalafgr.br

Rua Delfim Moreira, 33, 601 Centro $-3601-0570$ Juiz de Fora - Minas Gerais - Brasil maira.fajardolauff.edu.br
Doutora em Direito InTERnACIONAL E EUROPEU PELA UnIVERSité de Paris 1 Panthéon-Sorbonne (summa cum laude)

DOUTORA EM DIREITO INTERNACIONAL E INTEGRAÇÃo ECONÔMICA PELA UERJ

Mestre em Direito Público Internacional

E EUROPEU PELA Université de PARIS XI

Professora de Direito Internacional da FGV DireIto RIO e pesquisadora do Centro de Justiça e Sociedade DA FGV DIREITO RIO

\section{Maíra Fajardo Linhares Pereira}

Professora assistente de DiReito Empresarial da Faculdade de Direito da Universidade Federal de Juiz de Fora

MESTRE EM DiREITO INTERNACIONAL E INTEGRAÇÃo ECONÔMICA PELA UNIVERSIDADE dO ESTADO DO RIO DE JANEIRO 
